\title{
Corrosion Inhibition of Carbon Steel in 2.0M HCl Solution Using Novel Extract (Pulicaria undulate)
}

\author{
Amira Ezzat 1,2, Seham M. Abdel Motaal ${ }^{2}$, Amal S. Ahmed ${ }^{2}$, Hayanem B. Sallam ${ }^{2}$, Ahmed El-Hossiany ${ }^{1,3}$, \\ Abd El-Aziz S. Fouda $1, *$ (D) \\ Department of Chemistry, Faculty of Science, El-Mansoura University, Egypt \\ 2 Department of Chemistry, Faculty of Science (Girls), Al-Azhar University, Cairo, Egypt \\ 3 Delta for Fertilizers and Chemical Industries, Talkha, Daqahlia, 1179 Egypt \\ * Correspondence: asfouda@hotmail.com (A.E.-A.S.F.);
}

Scopus Author ID 56231506400

Received: 1.08.2021; Revised: 15.10.2021; Accepted: 18.10.2021; Published: 18.11.2021

\begin{abstract}
Plant Pulicaria undulate (PU) extract is examined as a corrosion inhibitor for carbon steel (CS) dipped in $2.0 \mathrm{M} \mathrm{HCl}$. The study was conducted utilizing ac impedance spectroscopy (EIS), Mass loss (ML), polarization (PDP) tests, and surface checks were utilized to illustrate the importance of this PU extract to prevent the corrosion process for CS. The influence of temperature and concentration of PU on the efficacy of inhibition were tested. The corrosion mechanism occurs when the PU extract molecules block the active center in the electrode surface. Langmuir isotherm is the isotherm that is applied in the process of adsorption. The effect of temperature at various temperatures on the corrosion efficacy was investigated in case of the presence and absence of the extract. Finally, thermodynamic parameters for the activation and adsorption processes were determined. Results of all methods used were in good agreement.
\end{abstract}

Keywords: Corrosion; CS; PU; EIS; PDP; EFM.

(C) 2021 by the authors. This article is an open-access article distributed under the terms and conditions of the Creative Commons Attribution (CC BY) license (https://creativecommons.org/licenses/by/4.0/).

\section{Introduction}

Corrosion is a naturally occurring process that affects our life and causes degradation to domestic gadgets, automobiles, airplanes, public roads, bridges, and distribution systems [1]. The main reason for the corrosion of metals is their tendency to reach a stable state. Several metal alloys are unstable and need to interact with the surrounding atmosphere to obtain minor energy by forming metal complexes [2]. CS is used in many industries such as refineries of oil and gas, bridges, and machines. Acidic media such as hydrochloric acid is used in the study of carbon steel decomposition due to acids are usually utilized materials for pickling of metals, cleaning boilers, acidizing oil wells, and recovery of ion exchangers. In addition to the previous, $\mathrm{HCl}$ is one of the acids that are widely used in improving the productivity (stimulation) of wells in oil and gas production, and over several years is utilized to raise the primary productivity of new wells as well as restore the productivity of old wells [3]. Acids enhance the metal dissolution rate and are responsible for material damage. To control the process of metallic corrosion, there are several tests, but one of the most significant practical tests used is utilizing corrosion inhibitors in the industrial field and academic studies and inhibit in the literary survey [4]. Corrosion inhibitors are those substances that, if added in lesser amounts to corrosion solutions, may lower or prevent the interaction of the metals with these environments. Inhibitors are those substances that, if added in lesser amounts to corrosion solutions, may lower or prevent 
the interaction of the metals with these environments. Organic compounds that contain heteroatoms such as nitrogen, oxygen, and sulfur atoms, in addition to the many other linkages that let them adsorb on the metal's surface and protect it from corrosion [5]. Corrosion inhibitors found in nature are environmentally beneficial, readily available, and inexpensive, with renewable sources of supply [6-16]. We investigated environmentally friendly materials (PU) extract as CS corrosion inhibitors in a $1 \mathrm{M} \mathrm{HCl}$ solution in this study, and we chose PU because of its properties: it contains many organic compounds that are ideal in the process of protecting metals, as well as its affordability and availability. The percentage protection productivity was calculated using three techniques: mass loss, electrochemical tests, and a combination of the two. The effect of higher temperatures on corrosion rate was measured and demonstrated.

\section{Materials and Methods}

\subsection{Materials and reagent.}

By diluting a reagent of analytical grade $\mathrm{HCl} 37$ percent with bi-distilled water, an acid corrosive environment $(1 \mathrm{M} \mathrm{HCl})$ was created. $\mathrm{C}(0.2$ percent $), \mathrm{Mn}(0.35$ percent $), \mathrm{P}(0.024$ percent), Si (0.003 percent), and balance Fe make up the composition of the applied CS in weight percent. For the ML tests, a $0.2 \mathrm{~cm}$ thick CS sheet was mechanically press-cut into 22 centimeter coupons. The samples were abraded with 400 and 2000 grade emery, cleaned and washed with acetone, sunk with bi-distilled water, and dried with filter paper. After that, the coupons were ready to be used in the corrosion tests. Using bi-distilled water, proper doses of the acid were created. In $2.0 \mathrm{M} \mathrm{HCl}, \mathrm{PU}$ extract dosages range from 50 to $250 \mathrm{ppm} .2 .2$. Preparation of plant extract and chemical structures of main constituents.

\subsection{Preparation of plant extract and Chemical structures of main constituents.}

Fine-powdered, air-dried whole plant of PU $(1.2 \mathrm{~kg})$ was extracted under reflux three times with $70 \%$ methanol/ water and then evaporated under reduced pressure and temperature. The purification was achieved on a Sephadex column $(35 \mathrm{~cm} 1.5 \mathrm{~cm})$ column using methanol as an eluent $[17,18]$. The main components found in the methanolic extract are 1) 5,7,2,3,4 Penta hydroxyl isoflavone-4'-O-b-glucopyranoside; 2) kaempferol; 3-kaempferol 3) O-b-glucoside; 4) quercetin; 5) quercetin3-O-b-glucoside; 6) quercetin 3-O-b-galactoside; 7) quercetin 3,7-di $\left.\mathrm{OCH}_{3} ; 8\right)$ caffeic acid.

\subsection{Mass loss (ML) tests.}

ML was achieved on CS coins with a cubic form $(2 \mathrm{~cm} \times 2 \mathrm{~cm} \times 0.03 \mathrm{~cm})$ in $2.0 \mathrm{M} \mathrm{HCl}$ presence and absence of altered doses of PU. Every sample was weighed by an electronic balance and then immersion in the acid environment $(50 \mathrm{ml})$. The dipping time was $120 \mathrm{~min}$ at the range of temperature from 303 to $333 \mathrm{~K}$. After dipping, the CS specimen was cleaned by alcohol washing, and the sample was massed again to measure the dissolution rate [19].

\subsection{Electrochemical tests.}

The CS was utilized for electrochemical tests (potentiodynamic polarization (PDP) and AC impedance (EIS) procedures). Prior to each investigation, the surface of CS coins was mechanically scratched with altered grades of emery papers and rinsed with bi-distilled water. Electrochemical techniques were carried out by utilizing Potentiostat/ Galvanostat (PCI4-G750) 
with software DC 105, EIS 300 for measurements, linked to a computer for data documented and saved. Each experiment was achieved on a newly abraded electrode utilizing a freshly prepared electrolyte. PDP technique was utilized through a cell involving three classic electrodes, which is the working electrode that is utilized CS for study, the second electrode is the reference electrode, and the third electrode is a platinum disk $(\varnothing 1 \mathrm{~mm}, 10 \mathrm{~mm})$. The samples were abraded with 400 and 2000 grade emery, cleaned and rinsed in acetone, buried in bidistilled water, and dried on filter paper. The coupons were then ready for use in the corrosion tests. Proper dosages of the acid were generated using bi-distilled water. PU extract doses in $2.0 \mathrm{M} \mathrm{HCl}$ vary from 50 to $250 \mathrm{ppm}$. All potentials were measured with the SCE in mind [20, 21]. The experiment was carried out with AC signals ranging from $(100 \mathrm{kHz}$ to $\mathrm{x} 0.1 \mathrm{~Hz})$ and peak amplitudes of $10 \mathrm{mV}$ at OCP. Using the Gamry Echem program and the charge transfer resistance to know the quality of protection, all of the impedance results were compatible with the suitable equivalent circuit.

\subsection{Morphology of the surface.}

\subsubsection{Atomic force microscopy (AFM).}

AFM adapted tests provide data on the surface examination of CS samples with metric linear purity. Measured Knowledge is implemented and valued through persecution From the SPM management computer code [22].

\subsubsection{Attenuated Total Reflection Infra-Red (ATR-IR).}

ATR-IR is the performance by utilizing Thermo Fisher Nicolet IS10, USA spectrophotometer [23].

\section{Results and Discussion}

\subsection{Mass loss (ML) method.}

The ML data of CS in $2.0 \mathrm{M} \mathrm{HCl}$ in attendance and the absence of altered doses of PU were achieved in Fig. 1 and are summarized in Table 1 . The $\eta \%$ was measured by utilizing the next Eq. [24,25]:

$$
\eta \%=\frac{C R_{\text {corr }}-C R_{\operatorname{corr}(i n h)}}{C R_{\text {corr }}} \times 100
$$

where $\mathrm{CR}_{\text {corr }}$ and $\mathrm{CR}_{\text {corr(inh) }}$ are the rates of $\mathrm{CS}$ sheet corrosion in presence and absence of altered doses of extract, correspondingly. Table 1 displays that the utilized extract hindrance the CR of $\mathrm{CS}$ in $2.0 \mathrm{M} \mathrm{HCl}$ at all doses under research. The $\mathrm{CR}$ is found to rely on the dose of the extract. $\eta \%$ improves with raising in the dose of PU [26].

Table 1. List of corrosion rate values at 120-minute immersion at different temperatures for $\mathrm{CS}$ in $2.0 \mathrm{M} \mathrm{HCl}$ in without and with of different doses of PU.

\begin{tabular}{c|c|c|c|c|c}
\multirow{2}{*}{$\begin{array}{c}\text { inh. } \\
\text { ppm }\end{array}$} & $25^{\circ} \mathrm{C}$ & $30^{\circ} \mathrm{C}$ & $35^{\circ} \mathrm{C}$ & $40{ }^{\circ} \mathrm{C}$ & $45^{\circ} \mathrm{C}$ \\
\cline { 2 - 6 } & 0.013 & 0.02 & 0.033 & 0.048 & 0.085 \\
\hline Blank & 0.0067 & 0.0102 & 0.0157 & 0.0212 & 0.034 \\
\hline 50 & 0.005 & 0.007 & 0.011 & 0.014 & 0.023 \\
\hline 100 & 0.0037 & 0.0057 & 0.0088 & 0.0096 & 0.0152 \\
\hline 150 & 0.002 & 0.003 & 0.004 & 0.006 & 0.007 \\
\hline 200 & 0.002 & 0.0028 & 0.0041 & 0.0051 & 0.0065
\end{tabular}




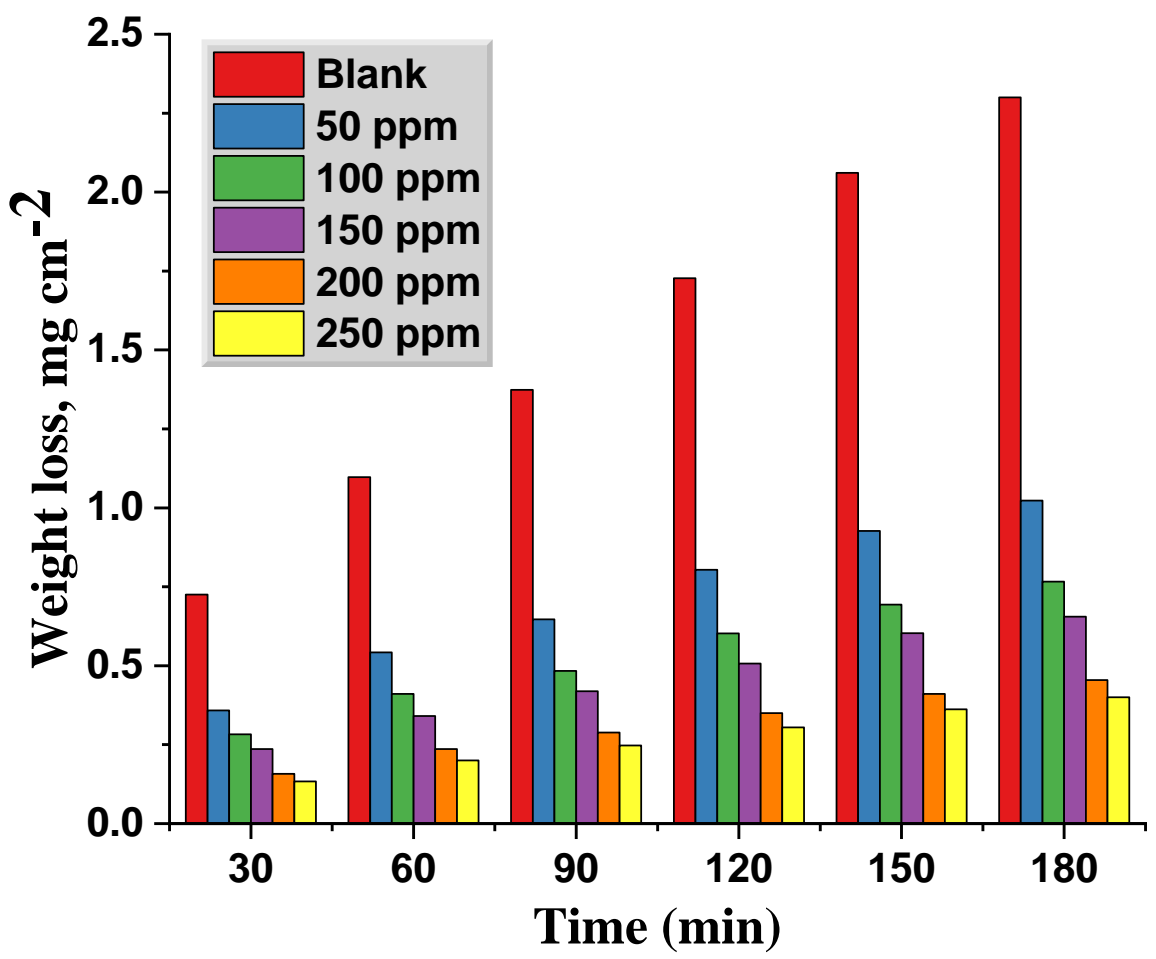

Figure 1. Plots of Mass loss vs. time for $\mathrm{CS}$ in $2.0 \mathrm{M} \mathrm{HCl}$ in case of the free acid and in the presence of various doses of PU extract at $25^{\circ} \mathrm{C}$.

\subsection{Effect of temperature.}

The results obtained from Table 2 showed that the $\eta \%$ are initiated to improve with raising the temperature from $25^{\circ} \mathrm{C}$ to $45^{\circ} \mathrm{C}$. This performance can be interpreted because the adsorption of PU molecules on the surface of CS is chemisorption [27].

Table 2. List of $\eta \%$ values at 120 -minute immersion at different temperatures for $\mathrm{C}-\mathrm{S}$ in $2.0 \mathrm{M} \mathrm{HCl}$ attendance and absence of altered dose of PU.

\begin{tabular}{c|c|c|c|c|c}
\multirow{2}{*}{$\begin{array}{c}\text { inh.] } \\
\mathbf{p p m}\end{array}$} & \multicolumn{5}{|c}{$\boldsymbol{\eta} \%$} \\
\cline { 2 - 5 } & $25^{\circ} \mathrm{C}$ & $30^{\circ} \mathrm{C}$ & $35^{\circ} \mathrm{C}$ & $40{ }^{\circ} \mathrm{C}$ & $45^{\circ} \mathrm{C}$ \\
\hline 50 & 47.54 & 49.51 & 52.59 & 56.32 & 60.01 \\
\hline 100 & 61.12 & 63.61 & 65.63 & 70.82 & 73.05 \\
\hline 150 & 70.73 & 71.63 & 73.51 & 80.16 & 82.06 \\
\hline 200 & 82.51 & 85.09 & 86.68 & 88.28 & 91.77 \\
\hline 250 & 84.26 & 86.38 & 87.72 & 89.52 & 92.34
\end{tabular}

The $\left(\mathrm{E}^{*}{ }_{\mathrm{a}}\right)$ of the dissolution process was calculated using Arrhenius eq. (2) [28]:

$$
\mathrm{k}_{\mathrm{corr}}=\mathrm{A} \exp \left(-\mathrm{E}_{\mathrm{a}}^{*} / \mathrm{RT}\right)
$$

Figure 2. refers to the straight lines given by a plot [ $\left.\operatorname{logk}_{\text {corr }} \mathrm{vs.} 1 / \mathrm{T}\right]$, which can calculate the $\mathrm{E}_{\mathrm{a}}{ }^{*}$ from their slopes which are illustrated in Table 3. $\Delta \mathrm{H}^{*}$ and $\Delta \mathrm{S}^{*}$ are measured from transition state theory utilizing eq. (3) [29]:

$$
\mathrm{k}_{\mathrm{corr}}=\mathrm{RT} / \mathrm{Nh} \exp \left(\Delta \mathrm{S}^{*} / \mathrm{R}\right) \exp \left(-\Delta \mathrm{H}^{*} / \mathrm{RT}\right)
$$

where $\Delta \mathrm{S}^{*}$ and $\Delta \mathrm{H}^{*}$ are entropy and activation enthalpy. Plot $\left[\log \mathrm{k}_{\text {corr }} / \mathrm{T}\right.$ vs. $\left.1 / \mathrm{T}\right]$ provided straight lines Figure 3. from their slopes $\Delta \mathrm{H}^{*}$ and their intercepts $\Delta \mathrm{S}^{*}$ can be calculated and reported in Table 3. The outcome data dictate that $\mathrm{E}_{\mathrm{a}}{ }^{*}$ decreases in the existence of PU extract than in its nonexistence, demonstrating chemical adsorption, the importance that the block of CS surface activities by bonding and hindering. Positive $\Delta \mathrm{H}^{*}$ data designate the endothermic activation procedure [30]. 


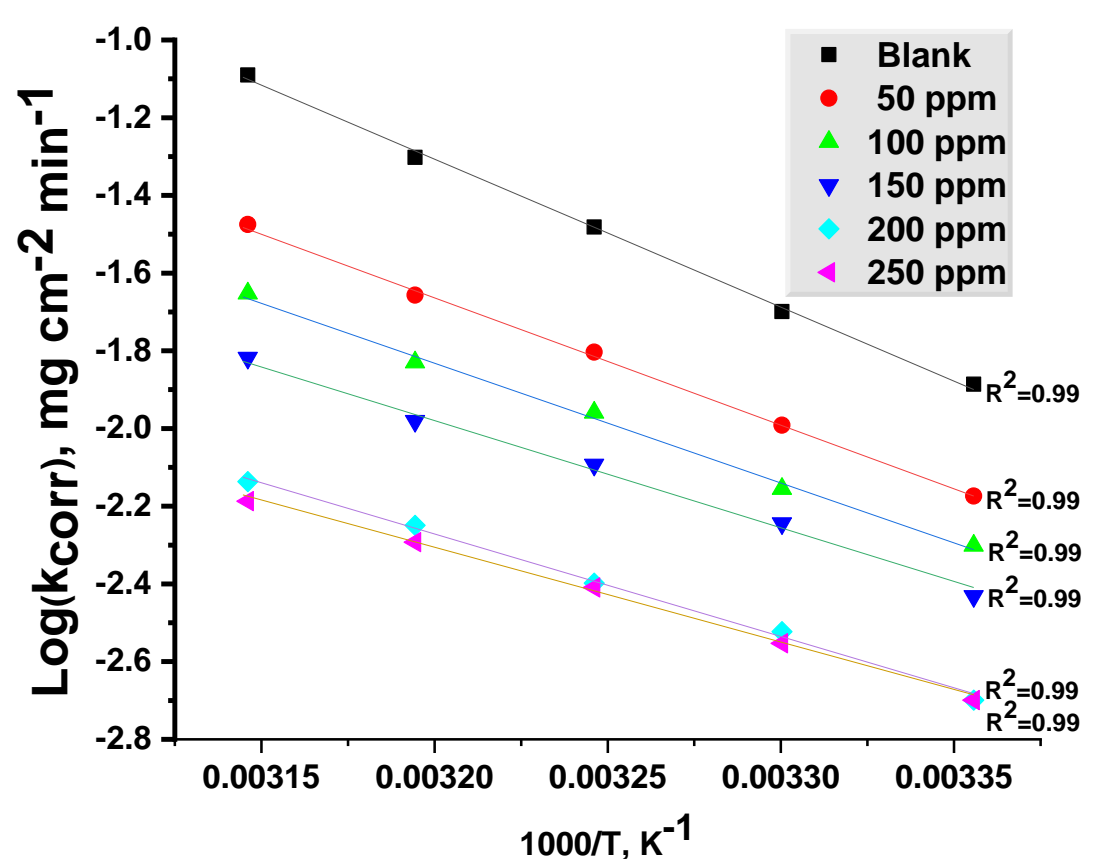

Figure 2. Plotting $\log \mathrm{CR}$ against $1 / \mathrm{T}$ for $\mathrm{CS}$ in the attendance and absence of various concentrations of PU.

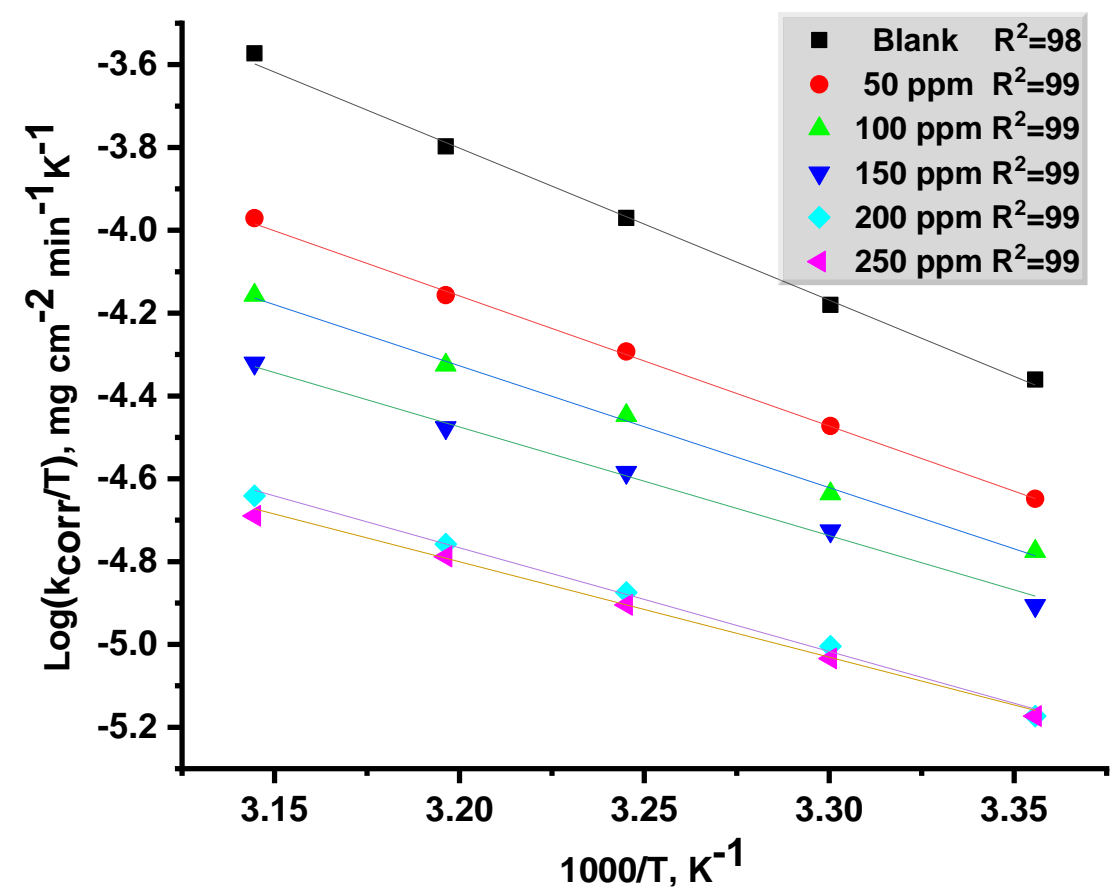

Figure 3. Plotting $\log \mathrm{CR} / \mathrm{T}$ against $1 / \mathrm{T}$ for $\mathrm{CS}$ in the attendance and absence of various concentrations of $P U$.

Table 3. Activation parameters $\left(\mathrm{E}_{\mathrm{a}}{ }^{*}, \Delta \mathrm{H}^{*}\right.$, and $\left.\Delta \mathrm{S}^{*}\right)$ for $\mathrm{CS}$ in the attendance and absence of various concentrations of $P U$.

\begin{tabular}{c|c|c|c}
$\mathbf{C}_{\text {inh, }} \mathbf{p p m}$ & $\mathbf{E}_{\mathbf{a}}{ }^{*} \mathbf{k J} / \mathbf{m o l}$ & $\Delta \mathbf{H}^{*}, \mathbf{k J} / \mathbf{m o l}$ & $-\Delta \mathbf{S}^{*}, \mathbf{J} / \mathbf{m o l} \mathbf{K}$ \\
\hline Blank & 72.39 & 71.13 & 42.51 \\
\hline 50 & 63.12 & 60.76 & 82.56 \\
\hline 100 & 59.11 & 56.30 & 100.10 \\
\hline 150 & 54.33 & 51.69 & 117.68 \\
\hline 200 & 50.99 & 47.71 & 136.10 \\
\hline 250 & 46.85 & 44.17 & 148.12
\end{tabular}

\subsection{Adsorption isotherms.}

The best isotherm among the experimental data and the isothermal functions was achieved in the range temperature studied utilizing the Langmuir isotherm adsorption [31], known by the next relation: 


$$
\frac{c}{\Theta}=\frac{1}{K_{a d s}}+C
$$

$\mathrm{K}_{\mathrm{ads}}$ is the adsorption equilibrium constant, and (C) is the extract's doses. For PU the linear regressions between $\mathrm{C} / \theta$ and $\mathrm{C}$ are shown in Figure 4 . The results showed that all linear lines and slopes are near 1 and designate that $\mathrm{PU}$ molecules were adsorbed in $2.0 \mathrm{M} \mathrm{HCl}$ on the CS surface. The $\mathrm{K}_{\mathrm{ads}}$ could be determined from the intercepts of lines on the $\mathrm{C} / \mathrm{\theta}$ axis, and $\mathrm{K}_{\mathrm{ads}}$ was related to the standard free adsorption energy, $\Delta \mathrm{G}^{\mathrm{o}}$ ads as follows:

$$
\Delta G_{a d s}^{o}=-R T \ln \left(55.5 K_{a d s}\right)
$$

The $\Delta \mathrm{G}^{\mathrm{o}}$ ads data at all temperatures are recognized in Table 3 . The $\left(\Delta \mathrm{H}^{\mathrm{o}}\right.$ ads. $)$ was measure agreeing to the Van't Hoff eqn.

$$
\log \mathrm{K}_{\mathrm{ads}}=-\Delta \mathrm{H}_{\mathrm{ads}}^{\mathrm{o}} / 2.303 \mathrm{RT}+\mathrm{constant}
$$

Plotting $\left(\log \mathrm{K}_{\mathrm{ads}}\right)$ vs. $(1 / \mathrm{T})$ gives a straight line as displayed in Figure 5, the slope $=(-$ $\Delta \mathrm{H}^{\mathrm{o}}$ ads $\left./ 2.303 \mathrm{R}\right)$, from this slope; the $\Delta \mathrm{H}^{\mathrm{o}}$ ads data was measured and is recorded in Table 4 . Then by applying the next balance:

$$
\Delta \mathrm{G}_{\text {ads }}^{\mathrm{o}}=\Delta \mathrm{H}_{\text {ads. }}^{\mathrm{o}}-\mathrm{T} \Delta \mathrm{S}_{\text {ads. }}^{\mathrm{o}}
$$

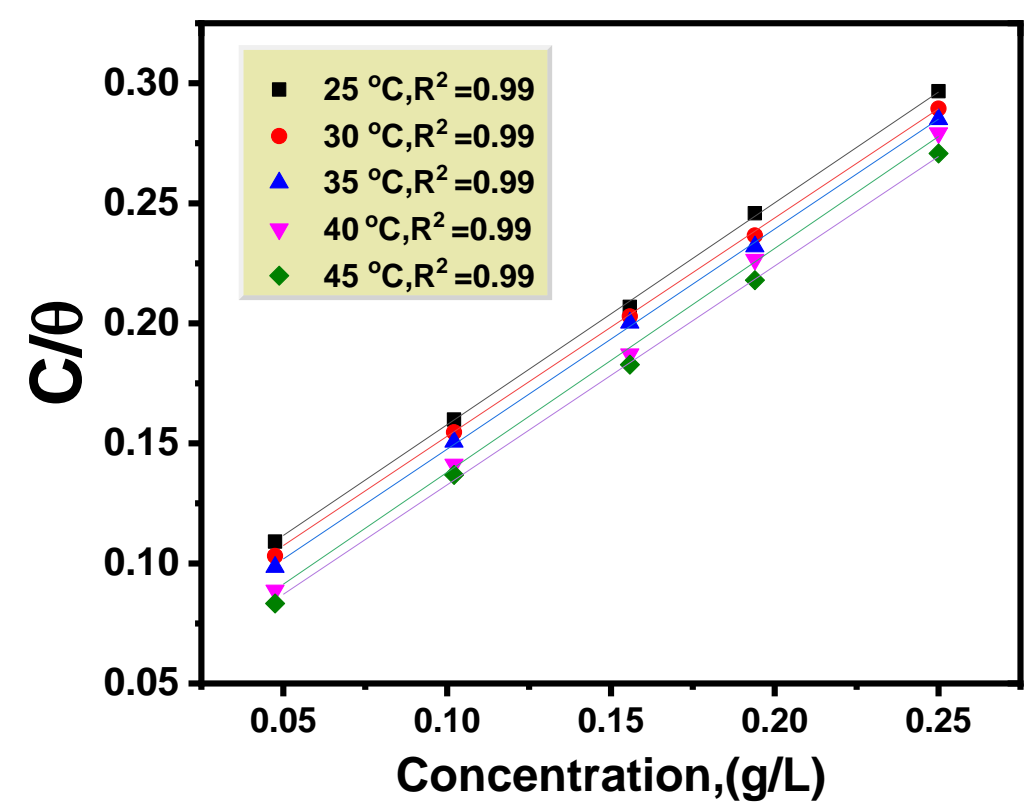

Figure 4. Langmuir plots for $\mathrm{CS}$ in $2.0 \mathrm{M} \mathrm{HCl}$, inclosing altered doses of $\mathrm{PU}$ at various temperatures $\left(25-45^{\circ} \mathrm{C}\right)$.

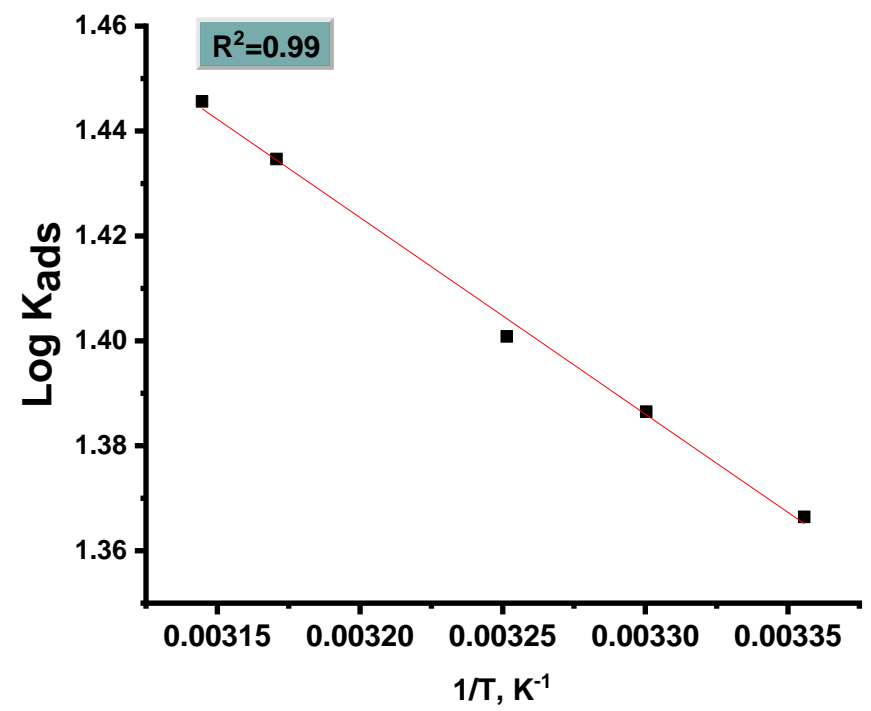

Figure 5. $\left(\log \mathrm{K}_{\mathrm{ads}}\right)$ versus $(1 / \mathrm{T})$ bends for the $\mathrm{CS}$ dissolution in $2.0 \mathrm{M} \mathrm{HCl}$ in the presence of PU. 
Table 4. Langmuir parameters of $\mathrm{PU}$ extract for $\mathrm{CS}$ in $2.0 \mathrm{M} \mathrm{HCl}$ obtained at altered temperatures.

\begin{tabular}{|c|c|c|c|c|c|}
\hline $\begin{array}{c}\text { Temp. } \\
{ }^{\circ} \mathrm{C}\end{array}$ & $\begin{array}{c}K_{\text {ads }} \times 1^{-3} \\
\mathbf{M}^{-1}\end{array}$ & $\mathbf{R}^{2}$ & $\begin{array}{c}-\Delta \mathbf{G}_{\text {ads }}^{0} \\
\mathbf{k J} \mathbf{~ m o l}^{-1}\end{array}$ & $\begin{array}{c}-\Delta \mathbf{H}_{\text {ads }}^{\circ} \\
\mathbf{k J} \mathrm{mol}^{-1}\end{array}$ & $\begin{array}{c}-\Delta S_{\text {ads }}^{\circ} \\
\mathrm{kJ} \mathrm{mol} \mathrm{K}^{-1}\end{array}$ \\
\hline 298 & 15.46 & 0.996 & 16.74 & \multirow{5}{*}{19.66} & 122.16 \\
\hline 303 & 16.63 & 0.997 & 17.20 & & 121.68 \\
\hline 308 & 17.83 & 0.999 & 17.66 & & 121.20 \\
\hline 313 & 22.71 & 0.999 & 18.58 & & 122.19 \\
\hline 318 & 24.52 & 0.999 & 19.08 & & 121.84 \\
\hline
\end{tabular}

The data of Table 4 confirm the spontaneous adsorption of PU extricate on the Through the negative data, CS surface obtained $\Delta \mathrm{G}^{0}$ ads, whose negative value (spontaneous), when negative values are lower than $20 \mathrm{~kJ} / \mathrm{mol}$, adsorption is physical adsorption. The exothermic process can relate to either physical or chemical adsorption. However, the kind of adsorption is determined by the value. The estimated values of $S^{0}{ }_{\text {ads }}$ showed that the adsorption process was accompanied by a drop in entropy [32].

\subsection{Electrochemical measurements.}

\subsubsection{PDP.}

In which an electrochemical solution's potential is formed and $\mathrm{E}_{\text {corr }}$ is measured, and $\mathrm{I}_{\text {corr }}$ from the Tafel curve ( $\mathrm{I}_{\text {corr }}$ ) slope is estimated, which is determined by the following equation [33]:

$$
\eta_{P P} \%=\theta x 100=\left[\frac{I_{\text {corr }}^{o}-I_{\text {corr }}}{I_{\text {corr }}^{o}}\right] \times 100
$$

where $\mathrm{I}^{\mathrm{o}}$ corr and $\mathrm{I}_{\text {corr }}$ are the current absence and attendance of PU, correspondingly. PDP bends for $\mathrm{CS}$ in $2.0 \mathrm{M} \mathrm{HCl}$, the existence and absence of PU dose are displayed in Figure 6. The parallel Tafel lines $\beta_{\mathrm{a}} \& \mathrm{c}$ indicate that both anodic and cathodic mechanisms do not impact by adding the PU to the corrosive environment. The data in Table 5 displays that the lower $\mathrm{I}_{\text {corr }}$ data in the existence of PU without affecting important exchanges in $\mathrm{E}_{\text {corr }}$ recommends that the PU is mixed kind [34]. In all doses, $\beta_{\mathrm{c}}$ is larger than $\beta_{\mathrm{a}}$, signifying that although the protection is under mixed control, the influence of PU on the cathodic is more distinct than anodic polarization.

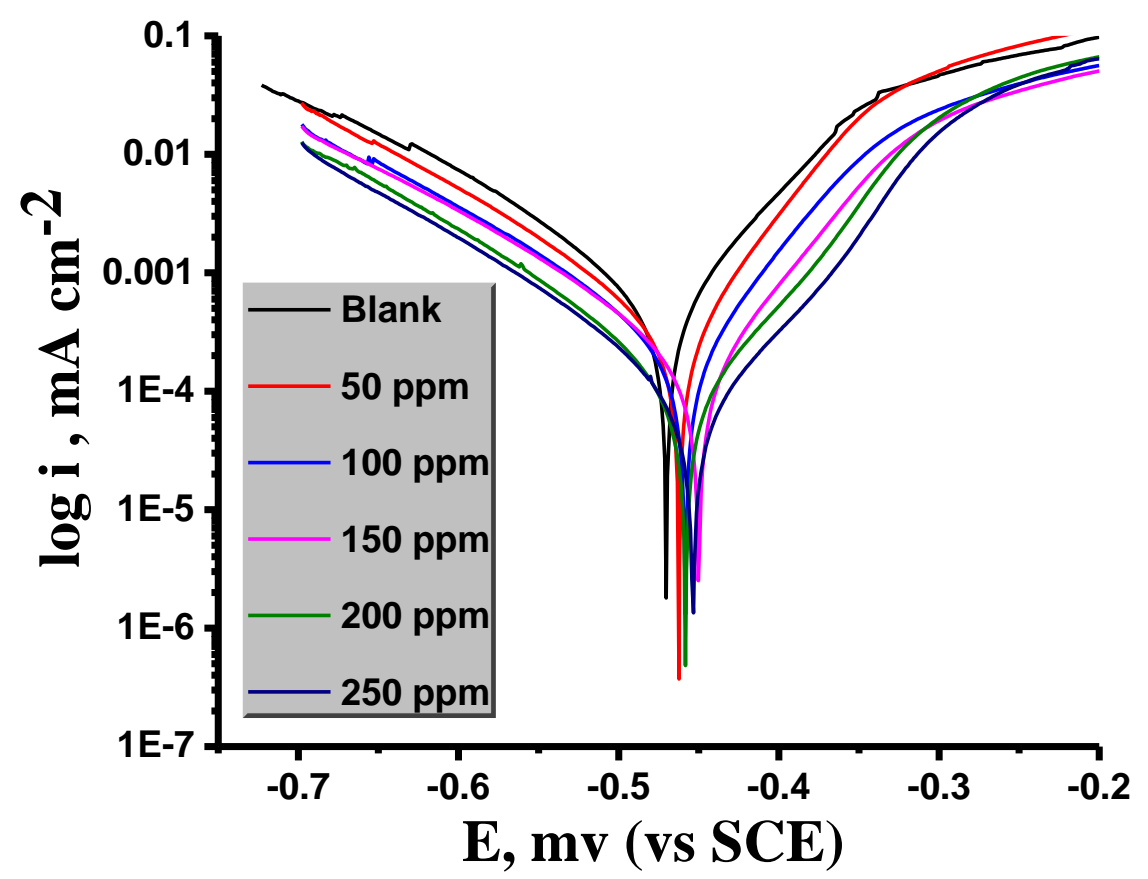

Figure 6. PDP bends for dissolution of CS presence and absence of altered doses of PU at $25^{\circ} \mathrm{C}$. 
Table 5. Effect of PU extract dose on the dissolution of $\mathrm{CS}$ in $2.0 \mathrm{M} \mathrm{HCl}$ at $25^{\circ} \mathrm{C}$.

\begin{tabular}{|c|c|c|c|c|c|c|c|}
\hline $\begin{array}{l}\text { Conc. } \\
\text { (ppm) }\end{array}$ & $\begin{array}{c}- \text { E }_{\text {corr, }} \\
\text { mV vs SCE }\end{array}$ & 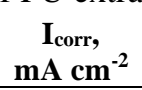 & $\begin{array}{c}\beta_{c} \\
m \operatorname{dec}^{-1}\end{array}$ & $\begin{array}{c}\beta_{a} \\
m \operatorname{dec}^{-1}\end{array}$ & $\begin{array}{l}\text { C.R } \\
\text { mpy }\end{array}$ & $\boldsymbol{\theta}$ & $\eta \%$ \\
\hline Blank & 470 & 522 & 111 & 72 & 238 & -- & -- \\
\hline 50 & 462 & 271 & 101 & 65 & 124 & 0.481 & 48.1 \\
\hline 100 & 458 & 172 & 98 & 60 & 78 & 0.670 & 67.0 \\
\hline 150 & 450 & 158 & 103 & 69 & 72 & 0.697 & 69.7 \\
\hline 200 & 458 & 110 & 97 & 68 & 51 & 0.789 & 78.9 \\
\hline 250 & 454 & 86 & 95 & 71 & 39 & 0.835 & 83.5 \\
\hline
\end{tabular}

\subsubsection{EIS results.}

Figure 7 displays the Nyquist and Bode diagrams for CS surface dipping at $2.0 \mathrm{M} \mathrm{HCl}$ absence and existence of different PU doses at $25^{\circ} \mathrm{C}$. As the PU dose decrease, the semicircle's diameter rises [35], by using the charge transfer resistance as a function of knowing the quality of protection by the next balance.

$$
\eta_{E I S} \%=\theta \times 100=\left[\left(R_{c t}-\frac{R_{c t}^{o}}{R_{c t}}\right) \times 100\right]
$$

$\mathrm{R}_{\mathrm{ct}}$ and $\mathrm{R}_{\mathrm{ct}}^{\circ}$ are the resistances in existence and absence PU, correspondingly.
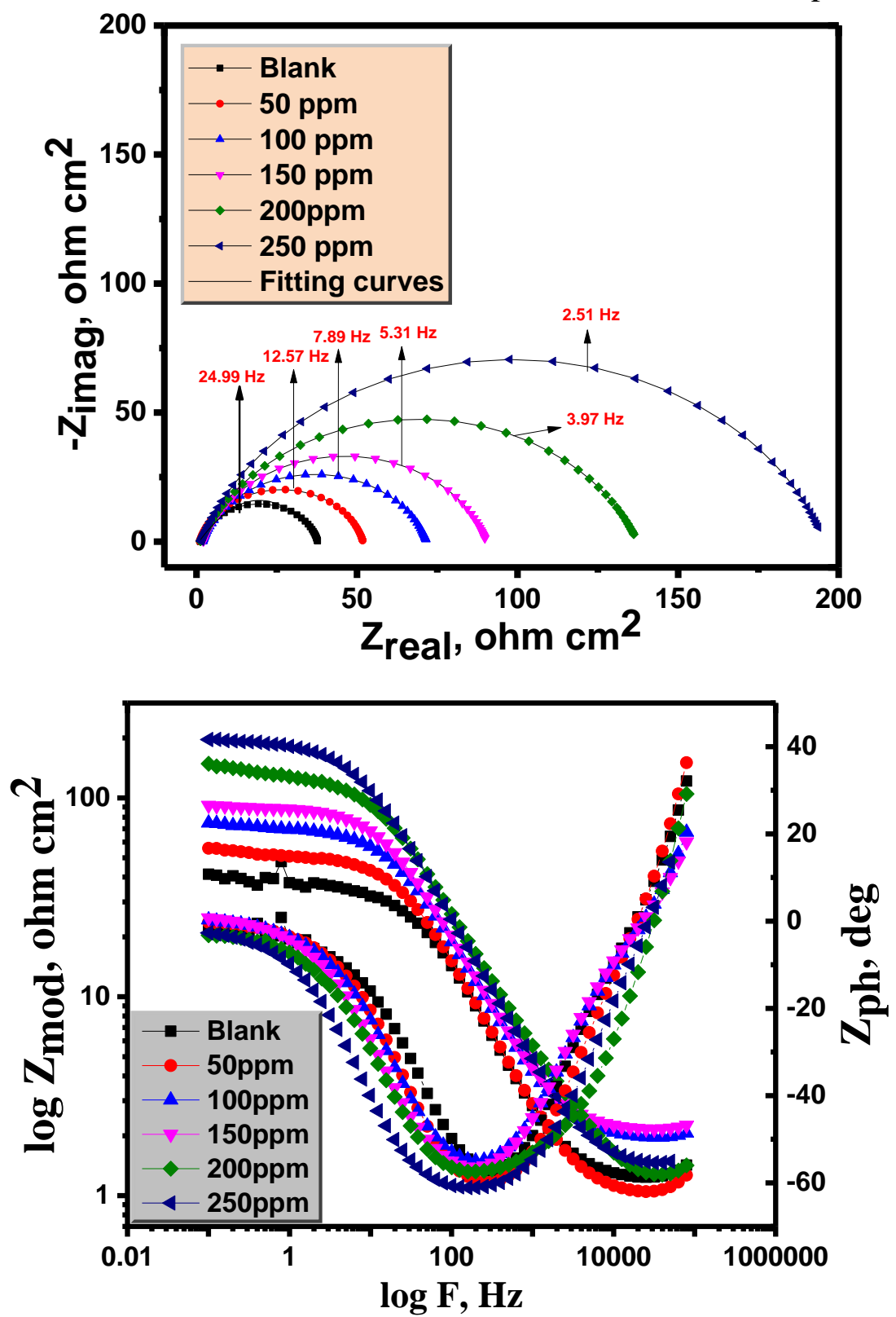

Figure 7. EIS Nyquist (a) and Bode (b) bends of CS in $2.0 \mathrm{M} \mathrm{HCl}$ solutions with and without of altered doses of $\mathrm{PU}$ at $25^{\circ} \mathrm{C}$. 
The matching circuit that defines CS alloy and electrolyte is established in Figure 8. Table 6 reported the EIS parameters. The deviation from the ideal semicircle was commonly due to the dispersion of frequencies and to the surface's inhomogeneity, grain boundaries, and impurities. Increasing the doses of the PU raises the charge transfer resistance $\left(\mathrm{R}_{\mathrm{ct}}\right)$ due to the increase in the thickness of the adsorbed layer and decreases the double-layer capacitance $\left(\mathrm{C}_{\mathrm{dl}}\right)$, due to the rise of the thickness of the electrical double layer or/and the lesser in the dielectric constant due to the replacement of the adsorbed water molecules on CS surface by the extract molecules", recommends that the PU molecules function by adsorption at the CS /interface [36].

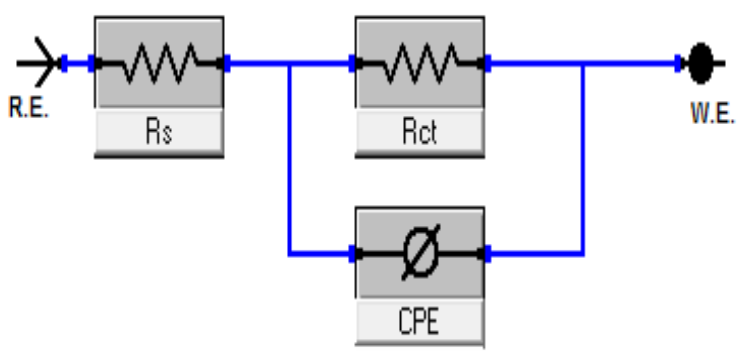

Figure 8. The employed equivalent circuit for appropriate the EIS values.

Table 6. EIS for the dissolution of $\mathrm{CS}$ in $2.0 \mathrm{M} \mathrm{HCl}$ attendance and absence of altered doses of PU at $25{ }^{\circ} \mathrm{C}$.

\begin{tabular}{|c|c|c|c|c|c|c|}
\hline $\begin{array}{l}\text { Conc. } \\
\text { (ppm) }\end{array}$ & $\begin{array}{c}Y_{0,} \\
\left(\mu \Omega^{-1} s^{n}{\mathrm{~cm}^{-2}}^{-2}\right) \\
\times 10^{-6}\end{array}$ & $\mathbf{n}$ & $\begin{array}{c}\mathbf{R}_{\mathrm{ct}}, \\
\mathbf{\Omega} \mathrm{cm}^{2}\end{array}$ & $\begin{array}{c}\mathrm{C}_{\mathrm{dl}}, \\
\mu \mathrm{F} \mathrm{\mathbf {cm } ^ { - 2 }} \\
\times \mathbf{x 0}^{-6}\end{array}$ & $\boldsymbol{\theta}$ & $\eta \%$ \\
\hline Blank & 215 & 0.857 & 36.5 & 115 & -- & -- \\
\hline 50 & 246 & 0.34 & 50.8 & 103 & 0.281 & 28.1 \\
\hline 100 & 244 & 0.817 & 69.8 & 98 & 0.477 & 47.7 \\
\hline 150 & 233 & 0.810 & 88.1 & 94 & 0.586 & 58.6 \\
\hline 200 & 231 & 0.775 & 136.1 & 85 & 0.732 & 73.2 \\
\hline 250 & 228 & 0.737 & 194.3 & 75 & 0.812 & 81.2 \\
\hline
\end{tabular}

3.6. Morphology of surface.

3.6.1. Attenuated total reflection infra-red (ATR-IR) analysis.

An FT-IR spectrophotometer is a useful tool for determining the presence of functional groups in PU and the interaction between functional groups and metal surfaces [37]. Figure 9 shows broad peaks of PU and PU with CS. After corrosion, there are some peaks displacement between the spectra of the PU and the adsorbed extract from the CS surface, and a few peaks disappear or become less noticeable. This implies that PU interacts with CS through the functional groups found in PU molecules, resulting in corrosion prevention.

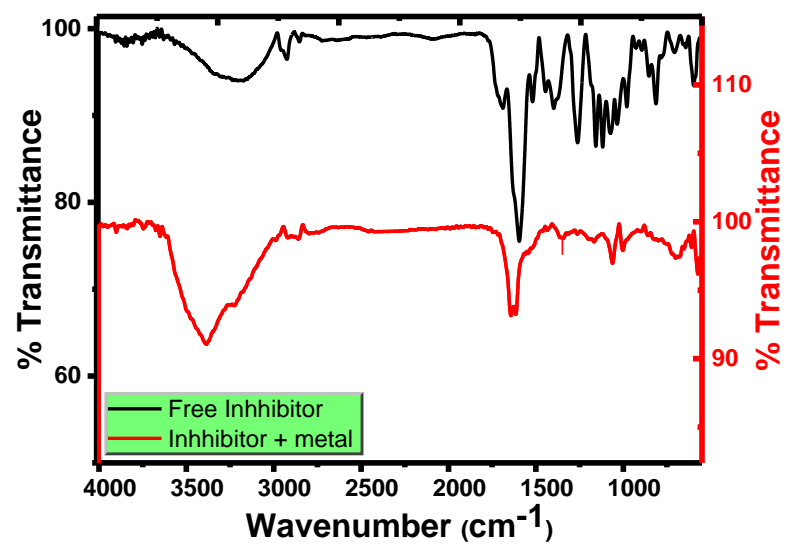

Figure 9. (a) CS ATR-FTIR after dipping in 2.0M HCl +300 ppm of PU; (b) PU before immersion. 
3.6.2. Atomic force microscopy (AFM) analysis.

The AFM is the most appropriate method for measuring surface topography as it can provide three-dimensional (3D); AFM considered the surface image details at the nano-to micro-scale to research the degree of inhibition in the test solution for dissolution of CS interfacing [38]. In the absence and existence of PU, Figure 10 displays the three dimensions (3D) using AFM morphologies for CS of 2.0M HCl. Root Mean roughness (Sq) square and mean roughness $(\mathrm{Sa})$. AFM picture in $2.0 \mathrm{M} \mathrm{HCl}$ shows $\mathrm{CS}$ surface corrosion with hard degradation but good quality in the presence of PU. The values $(\mathrm{Sa})$ and $(\mathrm{Sq})$ in Table 7 show that the surface of the CS is smoothed by the adsorbed surface layers of the PU on the CS [39].

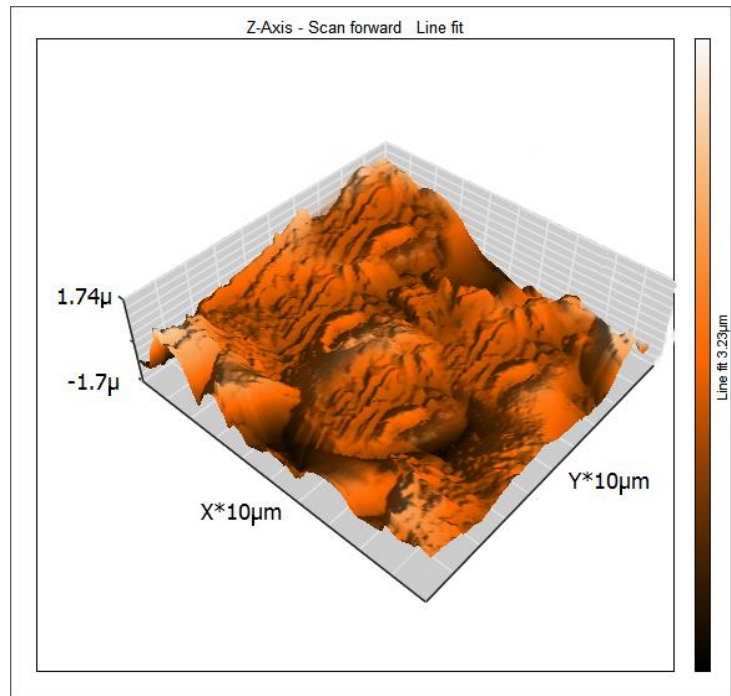

A) Blank

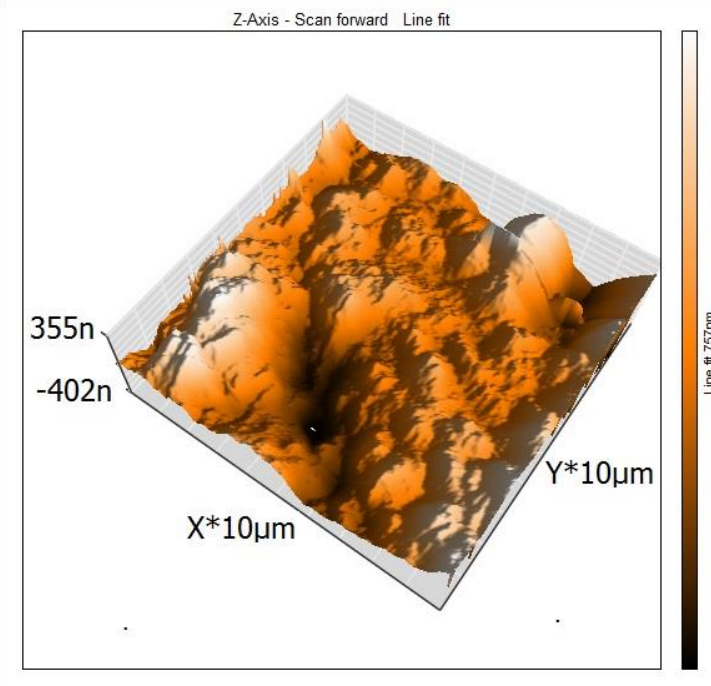

B) With 300 ppm of PU compound

Figure 10. Three-dimension AFM images for CS surface (A) Blank (CS with 2.0M HCl only); (B) CS immersed in $2.0 \mathrm{M} \mathrm{HCl}$ containing $300 \mathrm{ppm}$ of PU.

Table 7. AFM data for C-S surface with and without PU environment.

\begin{tabular}{c|c|c}
\multicolumn{1}{c}{$\begin{array}{c}\text { Specimen } \\
\text { CS immersed in 2.0M HCl only }\end{array}$} & $\begin{array}{c}\text { Average roughness (Sa) [nm] } \\
\text { [nm] }\end{array}$ \\
\hline CS immersed in 2.0M HCl and 300ppm PU (Sample) & 1143 & 1269 \\
\hline
\end{tabular}

\subsection{Mechanism of corrosion hindrance.}

From the obtained results, the $P U$ extract can be adsorbed on CS surface via physical and chemical adsorption.

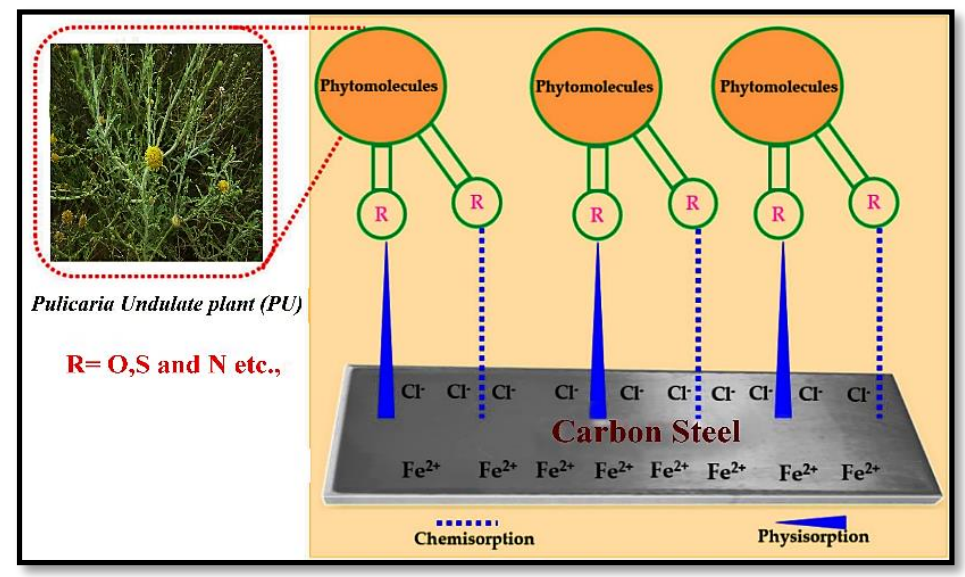

Scheme 1. Corrosion inhibition mechanism. 
"In physical adsorption, most of the extract molecules in $\mathrm{HCl}$ exist in protonated form (cation) which be in equilibrium with the conforming neutral form as: $[\mathrm{PU}]+\mathrm{H}^{+} \leftrightarrow\left[\mathrm{PUH} . \mathrm{Cl}^{-}\right.$ ions are first adsorbed on positively charged CS surface and create an excess negative charge towards the solution side of the metal and favor more adsorption of cations, then protonated extract molecules adsorb via electrostatic interactions and form a protective layer [40,41]. These complexes adsorbed onto the CS by force (Van Der Waals) to form protecting cover to prevent CS from corrosion". This $P U$ will present in the protonated form, so it can adsorb directly on the negative surface of CS in an acidic medium by electrostatic attraction, as shown in Scheme 1.

\section{Conclusions}

The examined PU extract shows high inhibition efficiency for CS corrosion in a solution of $2 \mathrm{HCl}$, and the inhibition was clarified by the adsorption fundamental. The adsorption of PU extract over CS surface obeyed Langmuir adsorption isotherm. The adsorption parameters indicated that the adsorption of PU extract on the CS surface was spontaneous. PDP procedures indicate that PU extract exhibits cathodic and anodic inhibition effects. AFM results for CS surface with PU extract indicate low roughness, meaning that the inhibitive film is formed on the surface of the metal. $\mathrm{C}_{\mathrm{dl}}$ diminishes while $\mathrm{R}_{\mathrm{ct}}$ rises by increasing the doses of PU, which can be attributed to the adsorbed PU molecules. There is good agreement between chemical and electrochemical techniques.

\section{Funding}

This research received no external funding

\section{Acknowledgments}

All our gratitude to the anonymous referees for their careful reading of the manuscript and valuable comments which helped in shaping this paper to the present form. We thank all laboratory staff of corrosion chemistry from the University of Mansoura (Egypt) for their kind cooperation.

\section{Conflicts of Interest}

The authors declare no conflict of interest.

\section{References}

1. Chung, I.-M.; Malathy, R.; Kim, S.-H.; Kalaiselvi, K.; Prabakaran, M.; Gopiraman, M. Ecofriendly Green Inhibitor from Hemerocallis Fulva against Aluminum Corrosion in Sulphuric Acid Medium. J. Adhes. Sci. Technol. 2020, 34, 1483-1506.

2. Mohammed, A.-R.I.; Solomon, M.M.; Haruna, K.; Umoren, S.A.; Saleh, T.A. Evaluation of the Corrosion Inhibition Efficacy of Cola Acuminata Extract for Low Carbon Steel in Simulated Acid Pickling Environment. Environ. Sci. Pollut. Res. 2020, 27, 34270-34288.

3. Verma, C.; Quraishi, M.A.; Ebenso, E.E. Microwave and Ultrasound Irradiations for the Synthesis of Environmentally Sustainable Corrosion Inhibitors: An Overview. Sustain. Chem. Pharm. 2018, 10, 134-147, https://doi.org/10.1016/j.scp.2018.11.001.

4. Agbaffa, E.B.; Akintemi, E.O.; Uduak, E.A.; Oyeneyin, O.E. Corrosion Inhibition Potential of the Methanolic Crude Extract of Mimosa Pudica Leaves for Mild Steel in $1 \mathrm{M}$ Hydrochloric Acid Solution by Weight Loss Method. Sci. Lett. 2021, 15, 23-42.

5. Vorobyova, V.; Skiba, M. Peach Pomace Extract as Efficient Sustainable Inhibitor for Carbon Steel against Chloride-Induced Corrosion. J. Bio-and Tribo-Corrosion 2021, 7, 1-11. 
6. Miralrio, A.; Espinoza Vázquez, A. Plant Extracts as Green Corrosion Inhibitors for Different Metal Surfaces and Corrosive Media: A Review. Processes 2020, 8, 942.

7. Bhardwaj, N.; Sharma, P.; Kumar, V. Phytochemicals as Steel Corrosion Inhibitor: An Insight into Mechanism. Corros. Rev. 2021, 39, 27-41.

8. Pourzarghan, V.; Fazeli-Nasab, B. The Use of Robinia Pseudoacacia L Fruit Extract as a Green Corrosion Inhibitor in the Protection of Copper-Based Objects. Herit. Sci. 2021, 9, 1-14.

9. Faiz, M.; Zahari, A.; Awang, K.; Hussin, H. Corrosion Inhibition on Mild Steel in $1 \mathrm{M}$ HCl Solution by Cryptocarya Nigra Extracts and Three of Its Constituents (Alkaloids). RSC Adv. 2020, 10, 6547-6562.

10. Mohanraj, M.; Aejitha, S. Natural Commiphora Caudata Extract as Corrosion Inhibitor for Mild Steel in Acid Media. In Proceedings of the AIP Conference Proceedings; AIP Publishing LLC, 2020; Vol. 2270, p. 50004.

11. Loto, R.T.; Loto, C.A. Inhibition Effect of Apium Graveolens, Punica Granatum, and Camellia Sinensis Extracts on Plain Carbon Steel. Cogent Eng. 2020, 7, 1798579.

12. Zaher, A.; Chaouiki, A.; Salghi, R.; Boukhraz, A.; Bourkhiss, B.; Ouhssine, M. Inhibition of Mild Steel Corrosion in 1M Hydrochloric Medium by the Methanolic Extract of Ammi Visnaga L. Lam Seeds. Int. J. Corros. 2020, 2020.

13. Ogunleye, O.O.; Arinkoola, A.O.; Eletta, O.A.; Agbede, O.O.; Osho, Y.A.; Morakinyo, A.F.; Hamed, J.O. Green Corrosion Inhibition and Adsorption Characteristics of Luffa Cylindrica Leaf Extract on Mild Steel in Hydrochloric Acid Environment. Heliyon 2020, 6, e03205.

14. Ali, A.E.; Badr, G.E.; El-Aziz, S.F.A. Citrus Sinensis Extract as a Green Inhibitor for the Corrosion of Carbon Steel in Sulphuric Acid Solution. Biointerface Res. Appl. Chem. 2021, 11, 14007-14020.

15. Reza, N.A.; Akhmal, N.H.; Fadil, N.A.; Taib, M.F.M. A Review on Plants and Biomass Wastes as Organic Green Corrosion Inhibitors for Mild Steel in Acidic Environment. Metals (Basel). 2021, 11, 1062.

16. Salleh, S.Z.; Yusoff, A.H.; Zakaria, S.K.; Taib, M.A.A.; Seman, A.A.; Masri, M.N.; Mohamad, M.; Mamat, S.; Sobri, S.A.; Ali, A. Plant Extracts as Green Corrosion Inhibitor for Ferrous Metal Alloys: A Review. $J$. Clean. Prod. 2021, 127030.

17. Ghorab, M.; Salah, S.; Ammar, H.; Mostafa, D.; Kassem, A.; Hossam, S.; Shalaby, E. Comparative Study for Optimization of Folic Acid Nanoparticles. BIOINTERFACE Res. Appl. Chem. 2020, 10, 5156-5160, https://doi.org/10.33263/BRIAC102.156160.

18. Fouda, A.S.; El-Dossoki, F.I.; El-Hossiany, A.; Sello, E.A. Adsorption and Anticorrosion Behavior of Expired Meloxicam on Mild Steel in Hydrochloric Acid Solution. Surf. Eng. Appl. Electrochem. 2020, 56, 491-500, https://doi.org/10.3103/S1068375520040055.

19. Okafor, P.C.; Ikpi, M.E.; Uwah, I.E.; Ebenso, E.E.; Ekpe, U.J.; Umoren, S.A. Inhibitory Action of Phyllanthus Amarus Extracts on the Corrosion of Mild Steel in Acidic Media. Corros. Sci. 2008, 50, 2310-2317.

20. Fouda, A.E.S.; Motaal, S.M.A.; Ahmed, A.S.; Sallam, H.B. Corrosion Protection of Carbon Steel in $2 \mathrm{M} \mathrm{HCl}$ Using Aizoon Canariense Extract. Biointerface Res. Appl. Chem. 2021, 12, 230-243, https://doi.org/10.33263/briac121.230243.

21. Fouda, A.S.; Abd El-Maksoud, S.A.; El-Hossiany, A.; Ibrahim, A. Corrosion Protection of Stainless Steel 201 in Acidic Media Using Novel Hydrazine Derivatives as Corrosion Inhibitors. Int. J. Electrochem. Sci. 2019, 14, 2187-2207, https://doi.org/10.20964/2019.03.15.

22. Boumhara, K.; Harhar, H.; Tabyaoui, M.; Bellaouchou, A.; Guenbour, A.; Zarrouk, A. Corrosion Inhibition of Mild Steel in 0.5 MH 2 SO 4 Solution by Artemisia Herba-Alba Oil. J. Bio-and Tribo-Corrosion 2019, 5, 19.

23. Elgyar, O.A.; Ouf, A.M.; El-Hossiany, A.; Fouda, A.S. The Inhibition Action of Viscum Album Extract on the Corrosion of Carbon Steel in Hydrochloric Acid Solution. Biointerface Res. Appl. Chem. 2021, 11, 1434414358.

24. Fouda, A.S.; Abdel Azeem, M.; Mohamed, S.A.; El-Hossiany, A.; El-Desouky, E. Corrosion Inhibition and Adsorption Behavior of Nerium Oleander Extract on Carbon Steel in Hydrochloric Acid Solution. Int. J. Electrochem. Sci. 2019, 14, 3932-3948, https://doi.org/10.20964/2019.04.44.

25. Fouda, A.S.; Rashwan, S.; El-Hossiany, A.; El-Morsy, F.E. Corrosion Inhibition of Zinc in Hydrochloric Acid Solution Using Some Organic Compounds as Eco-Friendly Inhibitors. J. Chem. Biol. Phys. Sci. 2019, 9, 124.

26. Fouda, A.S.; Abd El-Maksoud, S.A.; Belal, A.A.M.; El-Hossiany, A.; Ibrahium, A. Effectiveness of Some Organic Compounds as Corrosion Inhibitors for Stainless Steel 201 in $1 \mathrm{M} \mathrm{HCl}$ : Experimental and Theoretical Studies. Int. J. Electrochem. Sci. 2018, 13, 9826-9846, https://doi.org/10.20964/2018.10.36.

27. Fouda, A.S.; Ahmed, R.E.; El-Hossiany, A. Chemical, Electrochemical and Quantum Chemical Studies for Famotidine Drug as a Safe Corrosion Inhibitor for $\alpha$-Brass in $\mathrm{HCl}$ Solution. Prot. Met. Phys. Chem. Surfaces 2021, 57, 398-411.

28. Wasim, M.; Shoaib, S.; Mubarak, N.M.; Asiri, A.M. Factors Influencing Corrosion of Metal Pipes in Soils. Environ. Chem. Lett. 2018, 16, 861-879.

29. Fouda, A.E.A.S.; El-Gharkawy, E.S.; Ramadan, H.; El-Hossiany, A. Corrosion Resistance of Mild Steel in Hydrochloric Acid Solutions by Clinopodium Acinos as a Green Inhibitor. Biointerface Res. Appl. Chem. 2021, 11, 9786-9803, https://doi.org/10.33263/BRIAC112.97869803.

30. Fouda, A.S.; El-Maksoud, S.A.A.; El-Hossiany, A.; Ibrahim, A. Evolution of the Corrosion-Inhibiting 
Efficiency of Novel Hydrazine Derivatives against Corrosion of Stainless Steel 201 in Acidic Medium. Int. J. Electrochem. Sci. 2019, 14, 6045-6064, https://doi.org/10.20964/2019.07.65.

31. Fouda, A.S.; Abdel-Latif, E.; Helal, H.M.; El-Hossiany, A. Synthesis and Characterization of Some Novel Thiazole Derivatives and Their Applications as Corrosion Inhibitors for Zinc in $1 \mathrm{M}$ Hydrochloric Acid Solution. Russ. J. Electrochem. 2021, 57, 159-171.

32. Fouda, A.S.; Eissa, M.; El-Hossiany, A. Ciprofloxacin as Eco-Friendly Corrosion Inhibitor for Carbon Steel in Hydrochloric Acid Solution. Int. J. Electrochem. Sci 2018, 13, 11096-11112.

33. Fouda, E.-A.; El-Hossiany, A.; Ramadan, H. Calotropis Procera Plant Extract as Green Corrosion Inhibitor for 304 Stainless Steel in Hydrochloric Acid Solution. Zast. Mater. 2017, 58, 541-555, https://doi.org/10.5937/zasmat1704541f.

34. Hsissou, R.; Abbout, S.; Berisha, A.; Berradi, M.; Assouag, M.; Hajjaji, N.; Elharfi, A. Experimental, DFT and Molecular Dynamics Simulation on the Inhibition Performance of the DGDCBA Epoxy Polymer against the Corrosion of the E24 Carbon Steel in 1.0 M HCl Solution. J. Mol. Struct. 2019, 1182, 340-351.

35. Khaled, M.A.; Ismail, M.A.; El-Hossiany, A.A.; Fouda, A.E.-A.S. Novel Pyrimidine-Bichalcophene Derivatives as Corrosion Inhibitors for Copper in $1 \mathrm{M}$ Nitric Acid Solution. RSC Adv. 2021, 11, 25314-25333.

36. Motawea, M.M.; El-Hossiany, A.; Fouda, A.S. Corrosion Control of Copper in Nitric Acid Solution Using Chenopodium Extract. Int. J. Electrochem. Sci. 2019, 14, 1372-1387, https://doi.org/10.20964/2019.02.29.

37. Fouda, A.S.; Ibrahim, H.; Rashwaan, S.; El-Hossiany, A.; Ahmed, R.M. Expired Drug (Pantoprazole Sodium) as a Corrosion Inhibitor for High Carbon Steel in Hydrochloric Acid Solution. Int. J. Electrochem. Sci 2018, 13, 6327-6346.

38. Habibiyan, A.; Ramezanzadeh, B.; Mahdavian, M.; Kasaeian, M. Facile Size and Chemistry-Controlled Synthesis of Mussel-Inspired Bio-Polymers Based on Polydopamine Nanospheres: Application as EcoFriendly Corrosion Inhibitors for Mild Steel against Aqueous Acidic Solution. J. Mol. Liq. 2020, 298, 111974.

39. Fouda, A.S.; El-Ghaffar, M.A.A.; Sherif, M.H.; El-Habab, A.T.; El-Hossiany, A. Novel Anionic 4-Tert-Octyl Phenol Ethoxylate Phosphate Surfactant as Corrosion Inhibitor for C-Steel in Acidic Media. Prot. Met. Phys. Chem. Surfaces 2020, 56, 189-201, https://doi.org/10.1134/S2070205120010086.

40. Baymou, Y.; Bidi, H.; Touhami, M.E.; Allam, M.; Rkayae, M.; Belakhmima, R.A. Corrosion Protection for Cast Iron in Sulfamic Acid Solutions and Studies of the Cooperative Effect between Cationic Surfactant and Acid Counterions. J. Bio-and Tribo-Corrosion 2018, 4, 1-17.

41. Tasić, Ž.Z.; Mihajlović, M.B.P.; Radovanović, M.B.; Antonijević, M.M. New Trends in Corrosion Protection of Copper. Chem. Pap. 2019, 73, 2103-2132. 